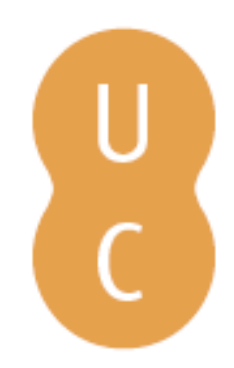

\title{
pompalina
}

\section{O Instituto, a sismologia em Coimbra e o intercâmbio luso-espanhol}

\author{
Autor(es): $\quad$ Leonardo, António José F.; Custódio, Susana; Batlló, Josep; Martins, \\ Décio; Fiolhais, Carlos
}

Publicado por: Imprensa da Universidade de Coimbra

URL

persistente:

URI:http://hdl.handle.net/10316.2/38453

DOI:

DOI:http://dx.doi.org/10.14195/978-989-26-0764-1_17

Accessed : $\quad$ 26-Apr-2023 02:03:57

A navegação consulta e descarregamento dos títulos inseridos nas Bibliotecas Digitais UC Digitalis, UC Pombalina e UC Impactum, pressupõem a aceitação plena e sem reservas dos Termos e Condições de Uso destas Bibliotecas Digitais, disponíveis em https://digitalis.uc.pt/pt-pt/termos.

Conforme exposto nos referidos Termos e Condições de Uso, o descarregamento de títulos de acesso restrito requer uma licença válida de autorização devendo o utilizador aceder ao(s) documento(s) a partir de um endereço de IP da instituição detentora da supramencionada licença.

Ao utilizador é apenas permitido o descarregamento para uso pessoal, pelo que o emprego do(s) título(s) descarregado(s) para outro fim, designadamente comercial, carece de autorização do respetivo autor ou editor da obra.

Na medida em que todas as obras da UC Digitalis se encontram protegidas pelo Código do Direito de Autor e Direitos Conexos e demais legislação aplicável, toda a cópia, parcial ou total, deste documento, nos casos em que é legalmente admitida, deverá conter ou fazer-se acompanhar por este aviso.

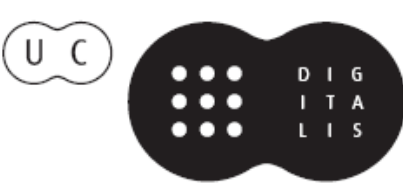


${ }^{1}$ Departamento de Física e Centro de Física Computacional, Faculdade de Ciências e Tecnologia da Universidade de Coimbra

${ }^{2}$ Centro de Geofísica e Instituto Geofísico

${ }^{3}$ Instituto D. Luís - IDL, Universidade de Lisboa

ajleonardo@iol.pt

\title{
O Instituto, a Sismologia em Coimbra e o Intercâmbio Luso-Espanhol
}

\author{
António José F. Leonardo ${ }^{1}$, Susana Custódio ${ }^{2}$, \\ Josep Batlló ${ }^{3}$, Décio Martins ${ }^{1}$ e Carlos Fiolhais ${ }^{1}$
}

Em 1908 foi admitido como praticante extraordinário do Observatório Meteorológico e Magnético da Universidade de Coimbra o bacharel Egas Fernandes Cardoso e Castro, a quem foi confiada a secção de sismologia. Egas de Castro publicou n'O Instituto, em Novembro de 1909, um dos primeiros estudos sismológicos do tremor de terra ocorrido em 23 de Abril desse ano com epicentro em Benavente. Nesta revista científica e literária, publicada pelo Instituto de Coimbra desde 1852 até 1981, saíram numerosos estudos nas mais diversas áreas científicas, incluindo a sismologia. $\mathrm{O}$ sismo de Benavente suscitou vários outros trabalhos em Portugal e Espanha. Originou também uma primeira tentativa, que veio a fracassar, de organização de um serviço sismológico em Portugal. Gerou ainda um intercâmbio com geofísicos espanhóis, tendo alguns deles publicado artigos sobre sismologia n' $O$ Instituto. O lente coimbrão Anselmo Ferraz de Carvalho publicou em 1925, nessa revista, um estudo sobre tremores de terra ao mesmo tempo que apresentava uma comunicação no congresso realizado em Coimbra das Associações Portuguesa e Espanhola para o Avanço das Ciências, intitulada Colaboração intima dos serviços sismológicos de Portugal e Espanha. Cientistas dos dois países ibéricos pretendiam, portanto, já nessa altura dar passos para estudar a sismologia à escala internacional.

\section{INTRODUÇÃO}

O percurso histórico da sismologia está, de forma indelével, ligada a Portugal. Com efeito, o fenómeno dos tremores de terra tornou-se um importante objecto de estudo a partir do grande sismo de Lisboa de 1755, que atingiu de forma dramática a cidade de Lisboa. O governo português da época, encabeçado pelo Marquês de Pombal, adoptou uma postura racional perante um acontecimento de origem natural e deu, de modo brilhante, um dos primeiros exemplos de resposta do Estado a uma emergência sísmica (ALMEIDA 2009). Ainda tomou a iniciativa de distribuir em larga escala questionários sismológicos com o intuito de avaliar os efeitos do terramoto nas pessoas, construções e terrenos, ao mesmo tempo que solicitava informações sobre outros sismos anteriores (PEIXOTO et al. 1986, p. 264). O sismo de Lisboa 
desencadeou numerosos estudos, da autoria de portugueses e estrangeiros, bem como a elaboração de catálogos de outras catástrofes naturais sentidas até à época em todo o globo, de forma a dar conta do que então era considerada a "epilepsia da Terra" (MENDONÇA 1758).

O estabelecimento da sismologia como área científica assentou, principalmente, em dois factores: 1) no desenvolvimento de um corpo teórico que descrevia a natureza ondulatória dos sismos, que passaram a estar relacionados com causas, na época de origem desconhecida, radicadas no subsolo terrestre, e 2) na invenção de instrumentos de registo da actividade sísmica que podiam medir os movimentos do solo. Grandes avanços nesta área só vieram, porém, a ocorrer no decorrer do século XIX e nas primeiras décadas do século XX. Após terem sido escritas as equações do movimento ondulatório em meios praticamente elásticos pelos franceses Augustin-Louis Cauchy e Siméon-Denis Poisson entre 1828 e 1831, ficou clara a existência de duas ondas sísmicas que se propagavam a velocidades diferentes: foram denominadas longitudinais e transversais pelo irlandês Georges Stokes em 1849. A obtenção de sismogramas ao longo da segunda metade do século XIX, tendo por base o aperfeiçoamento do sismógrafo, permitiu novos avanços, designadamente os alcançados pelo geólogo inglês Richard Oldham que, a partir da análise de sismogramas do sismo de 1897, na Índia, foi o primeiro a identificar correctamente as ondas primárias (P), de compressão e longitudinais, as ondas secundárias (S), de deslocação transversal e mais lentas que as ondas $P$, e as ondas de superfície, que se propagam à superfície terrestre e que já haviam sido previstas pelo físico inglês Lord Rayleigh em 1885 (HOWELL 1990). A capacidade de interpretação de sismogramas, obtidos em diversos sítios do planeta, contribuiu para uma forte expansão da sismologia e para a sua aplicação ao melhor conhecimento do interior da Terra.

A quantificação dos tremores de terra foi também um dos primeiros objectivos da sismologia. Os primeiros métodos incidiram na formulação de escalas numéricas baseadas numa síntese dos efeitos observados, em particular naqueles com maior relevância para a actividade humana. Assim, as primeiras escalas, que registavam a intensidade sísmica por comparação com os efeitos registados noutros casos, foram aperfeiçoadas de modo a reduzir a sua subjectividade. As escalas de intensidade desenvolvidas, independentemente pelo italiano Michele Stefano de Rossi, em 1874, e pelo suíço François Alphonse Forel, em 1881 começaram por ter repercussão internacional. Ambas apresentavam dez níveis que se iniciavam por um tremor muito leve, apenas registado por um bom sismógrafo, e que acabavam num grau de uma agitação causadora de uma enorme destruição. Os dois investigadores publicaram, em 1883, uma escala conjunta à qual foi dado o nome de Rossi-Forel, que haveria de ser a mais usada para avaliar os sismos nas décadas seguintes. O italiano Giuseppe Mercalli introduziu, em 1902, modificações nessa escala, mantendo os dez graus mas amplificando a sua descrição. A escala que ainda hoje é usada, embora com algumas modificaçôes, às quais está associado o nome de Mercalli, foi proposta por Adolfo Cancani em 1904. Contém dois níveis de intensidade a mais que apenas deviam ser aplicados a sismos mais sérios, perfazendo um total de doze graus (FERRARI E GUIDOBONI 2000; MUSSON et al. 2010).

No início do século XX persistia uma grande dificuldade em relacionar a intensidade sísmica, obtida através das referidas escalas, com uma grandeza física que 
permitisse obter uma graduação contínua. Contudo, Cancani efectuou também a primeira tentativa relativamente bem sucedida de relacionar cada grau da escala de Mercalli com valores limites da aceleração do movimento sísmico (CASTRO 1909, pp. 586-587). ${ }^{1}$

A afirmação da sismologia como um ramo das geociências só foi possível com o aparecimento de instituiçôes dedicadas ao seu estudo, em paralelo com o interesse suscitado principalmente por fenómenos sísmicos devastadores. Não é de admirar que o primeiro grupo organizado de investigadores nesta área - a Sociedade Sismológica do Japão - tenha surgido neste país, logo após o sismo de Yokohama de 1880. Esta sociedade era liderada por sismólogos britânicos, nos quais se incluía John Milne. Uma segunda associação surgiu em Itália, país situado numa zona sísmica: em 1895, foi fundada a Sociedade Sismológica Italiana (VALONE 1998, pp. 747-748), à qual pertenceu o físico da Universidade de Coimbra António dos Santos Viegas (Observações Meteorológicas, Magnéticas e Sismológicas, 1914, p. VIII).

\section{A fundação do instituto e os Primeiros sismógrafos em Portugal}

O escritor Joaquim José Moreira de Mendonça publicou em 1758 uma história dos terramotos com um título extenso, como era uso na época: a História Universal dos Terremotos que tem havido no mundo, de que ha noticia, desde a sua creaçaó até o seculo presente: com huma narraçam individual do terremoto do primeiro de Novembro de 1755, e noticia verdadeira dos seus effeitos em Lisboa, todo Portugal, Algarves, e mais partes da Europa, Africa, e América, aonde se estendeu: e huma dissertaçaó phisica sobre as causas geraes dos terremotos, seus effeitos, differenças e prognosticos: e as particulares do ultimo. Como o título evidencia, pretendia o autor não só descrever o terramoto que havia ocorrido em Lisboa, três anos antes, mas também catalogar, com base nos registos existentes, todos os sismos sentidos no mundo até 1755 e dissertar sobre a forma como os eventos sísmicos eram vistos por estudiosos estrangeiros, incluindo a discussão das suas possíveis causas. Trata-se de uma obra seminal na sismologia em Portugal, não apenas pelo seu valor descritivo, que esteve na base de um estudo sismológico realizado, em 1909, por Luís Pereira de Sousa, mas também pela tentativa de dar explicaçôes físicas de um fenómeno cuja origem divina ainda era aceite por muitos.

No seu texto de 1803 intitulado Sobre a causa natural do famoso Terramoto de Lisboa no ano de 1755, o filósofo natural Teodoro de Almeida (1722-1804), padre da Congregação do Oratório que esteve exilado em Espanha e França, descreveu algumas das consequências do abalo telúrico, seguidas das reflexôes que fundamentavam as explicações científicas da sua ocorrência. ${ }^{2}$ Vários outros autores portugueses da época dissertaram sobre as causas deste abalo (nomeadamente os médicos António

\footnotetext{
${ }^{1}$ Cancani baseou-se em fórmulas simples e experimentalmente verificadas, que avaliavam a aceleração máxima necessária para causar os efeitos sísmicos observados em construções. Essas fórmulas tinham sido obtidas por Fusakichi Omori, professor de sismologia da Universidade de Tóquio.

${ }^{2}$ Publicado em anexo no livro Lisboa destruida : poema / Theodoro de Almeida. Lisboa: Na oficina dos Conselhos de Guerra e do Almirantado. Anno M.DCCC.III.
} 
Ribeiro Sanches e José Alvares da Silva), citando alguns as ideias primitivas dos filósofos da antiguidade, enquanto outros apelavam à aplicação do moderno método baconiano (CARVALHO 1987).

O interesse no estudo dos fenómenos sísmicos não conduziu, no imediato, a grande evolução da sua compreensão científica, ficando esta dependente da construção de aparelhos que permitissem efectuar registos precisos da deslocação do solo, da sua velocidade e/ou aceleração, num dado ponto da superfície terrestre - os sismógrafos. Apesar de terem sido desenhados e construídos vários instrumentos sísmicos e sismoscópios $^{3}$ durante o século XVIII, os primeiros sismógrafos dignos desse nome só vieram a surgir em meados do século XIX (FERRARI 1998, pp. 528-530). É também por isso que, em Portugal, o tema da sismologia se foi dissipando à medida que se ia atenuando a memória do drama de 1755.

O interesse pelas ciências geofísicas acentuou-se, porém, na década de 1850, no quadro de um novo ambiente político, marcado por um sentimento regenerador da nação. Após as invasões francesas, ocorridas no início do século, e dos anos de guerra civil, obtiveram-se, a meio do século XIX, as condições propícias à concretização de medidas de reacção ao atraso científico e tecnológico do reino. Em Lisboa, foi fundado em 1854 um Observatório Meteorológico, ao qual foi dado o nome do Infante D. Luís e associado à Escola Politécnica, ao passo que em Coimbra se retomavam as observações meteorológicas no Gabinete de Física, cujos resultados passaram a ser publicados numa revista científica e literária - $O$ Instituto. Esta publicação emanava da sociedade académica com o mesmo nome que tinha sido criada em Coimbra em 1852. O Instituto de Coimbra englobou uma parte dos associados da Academia Dramática, na sua maioria jovens professores da Universidade, que ao cultivo das Letras e Artes decidiram aliar o estudo e a disseminação da Ciência em Portugal, que sabiam estar relacionada com o progresso material. Assim, na nova associação, para além de uma classe dedicada à Literatura e Belas Artes, outras duas foram devotadas às Ciências Morais e Sociais e às Ciências Físico-Matemáticas (LEONARDO 2009). Desde logo alguns membros do Instituto pediram a criação de um observatório meteorológico e magnético em Coimbra, semelhante ao lisboeta, um desiderato que só seria atingido em 1864, em grande parte por iniciativa de Jacinto António de Sousa, professor de Física da Universidade e um dos fundadores do Instituto (LEONARDO 2011).

Em ambos os observatórios se privilegiaram as observaçōes meteorológicas e magnéticas. No entanto, Joaquim Henriques Fradesso da Silveira (1825-75), lente de Física da Escola Politécnica de Lisboa e na altura director do Observatório Infante D. Luís, fez uma primeira tentativa em 1864 de instalar uma estação sismográfica em Lisboa. Neste mesmo ano, Fradesso da Silveira endereçou uma carta a Alexis Perrey, sismólogo francês que tinha compilado um extenso catálogo de tremores de terra entre 1843-71, solicitando que lhe fosse indicado um sismógrafo simples para instalar em Lisboa. Todavia a resposta de Perrey terá sido desencorajadora, não se concretizando a pretendida aquisição (PEIXOTO et al. 1986, pp. 270-271).

\footnotetext{
${ }^{3}$ Instrumentos que detectam os efeitos de tremores de terra, sem terem a capacidade de registarem a actividade sísmica.
} 
A existência do Instituto de Coimbra e, em particular do respectivo periódico que reportava a actividade científica e académica na então única universidade portuguesa, terá encorajado os seus sócios a envolverem-se em novas áreas científicas. António dos Santos Viegas (1835-1814), professor catedrático de Física e sucessor de Jacinto de Sousa na direcção do Observatório Meteorológico e Magnético da Univesidade, que acumulou, entre 1885-86, com a presidência do Instituto e, entre 1890-92 e 1906-7, com a Reitoria da Universidade, foi um dos pioneiros da sismologia portuguesa. Em 1891, ajudou na aquisição de um primeiro sismógrafo para o Observatório (um aparelho Angot B, N. ${ }^{\circ} 5388$, construído na casa Breguet), que se manteve em funcionamento até 1914/15 (CUSTÓDIO et al. 2010).

Nos Açores os estudos sismográficos começaram em 1902, com a instalação de sismógrafos em Ponta Delgada e Horta. Dois anos depois foi instalado no Observatório Astronómico de Lisboa (Tapada da Ajuda) um tromómetro de Bosch que registava movimentos sísmicos. Este último nunca funcionou regularmente por falta de pessoal e por dificuldades de instalação (PEIXOTO et al. 1986, p. 271).

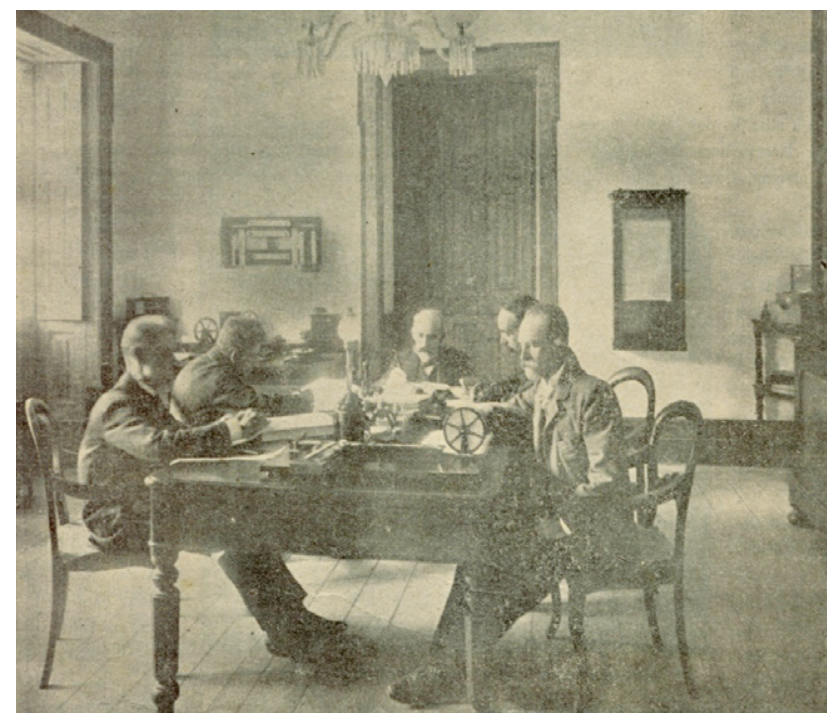

Figura 1: Santos Viegas (ao centro) e os seus ajudantes no Observatório Meteorológico e Magnético da Universidade de Coimbra (Observaçōes Meteorológicas, Magnéticas e Sismológicas, 1914).

A Sismologia em Coimbra e O SISMo de BenAVENTE de 1909

Tendo sido o Observatório da Universidade o precursor nacional dos estudos sismográficos, Santos Viegas (figura 1) cuidou de não descurar a área, procurando aperfeiçoar os serviços prestados. O sismógrafo de Angot terá funcionado com alguma regularidade, o que se comprova pela aquisição de papel fotográfico para o sismógrafo e uma anotação com data de 24 de Abril de 1901 que regista um tremor de terra em Lisboa e Algarve (SANTOS 1995, p. 146), apesar de os resultados não terem 
vindo a lume em qualquer publicação. Verificou-se, na transição de século, que a sensibilidade e a velocidade de registo deste aparelho não eram suficientes para sustentar uma secção de sismologia, pelo que, em 1900, Santos Viegas promoveu a aquisição de um sismógrafo Milne, de pêndulo horizontal, ao Observatório inglês de Kew, instrumento que chegou a Portugal no ano seguinte (idem, pp. 147-148). Embora as obras de construção de um pavilhão tenham sido logo iniciadas, a instalação do novo aparelho, que registava movimentos sísmicos da direcção este-oeste (E-W), apenas foi concluída em 1904.

Como aconteceu com outras instalações científicas nacionais dessa época, as limitações derivadas da falta de pessoal técnico para tabular com regularidade os registos impediu, nos anos seguintes, a publicação dos resultados. Apenas em 1908 se conseguiu obter os serviços de um recém-graduado na Faculdade de Filosofia da Universidade, Egas Fernandes Cardoso e Castro (1885-?). Este bacharel foi admitido como praticante extraordinário sendo, no ano seguinte, encarregado da nova secção de sismologia. Embora não remunerado, o trabalho de Egas de Castro permitiu a publicação das observações sísmicas de 1909. Estas vieram juntar-se às observações meteorológicas e magnéticas que já tinham sido compiladas ao longo das quatro décadas anteriores, suscitando a alteração do nome da publicação anual do Observatório (OBSERVAÇŌESS Meteorológicas, Magnéticas e Sísmicas, 1910). Com a criação da secção de sismologia, ficou completa a investigação na área das ciências geofísicas em Coimbra. A participação de Egas de Castro foi devidamente destacada por Santos Viegas (idem, p. VIII).

As observaçóes sísmicas publicadas pelo Observatório de 1909 a 1914 descreviam todos os eventos sísmicos detectados, que foram classificados em: tremor domesticus (epicentro a menos de $500 \mathrm{~km}$ ), vicinus (epicentro de 500 a $3000 \mathrm{~km}$ ), remotus (epicentro de 3000 a $10000 \mathrm{~km}$ ) e ultimus (epicentro a mais de $10000 \mathrm{~km}$ ). Para cada sismo, eram indicados os instantes: de início do tremor (V1), de início da segunda fase (V2), de início da fase principal (B), de máxima amplitude (M) e de fim do tremor (F). Eram registadas também a semi-amplitude máxima em milímetros $(\mathrm{A})$ e a inclinação máxima em segundos de arco (I) (idem). Esta era uma adaptação do sistema adoptado pela Associação Britânica para o Avanço da Ciência.

Por coincidência, foi também em 1909 que ocorreu o sismo mais forte sentido na Península Ibérica no século XX. Este abalo veio relançar o debate sobre a necessidade de criar um serviço nacional de sismologia. O tremor de terra teve o seu epicentro próximo da vila de Benavente (figura 2), mas os seus efeitos devastadores fizeram-se sentir numa vasta região, na margem sul do Tejo, cerca de $40 \mathrm{~km}$ a montante de Lisboa. Registaram-se 47 mortos e os danos patrimoniais foram consideráveis: cerca de $40 \%$ dos edifícios de Benavente ruíram, tendo de ser demolidos e só $20 \%$ sofreram danos menores (FONSECA 2010). O sismógrafo de Coimbra foi o único em território português a registar este evento, ${ }^{4}$ no dia 23 de Abril o seguinte registo:

\footnotetext{
${ }^{4}$ Há referências à construção de um transformador electro-automático de velocidade aplicado a um pêndulo vertical, no Observatório da Marinha, um dispositivo, da autoria do vice-almirante Augusto Ramos da Costa, que permitia distinguir as fases de um sismograma. Este aparelho estava a funcionar quando se deu o sismo de Abril de 1909. Foi publicada uma descrição deste macrosismógrafo no Bulletin n. 5 de la Societé Belge de Astronomie, em 1910 (COSTA 1931).
} 
"Desde as 13h-55m,4 deste dia o pêndulo mostrou-se inquieto até ás $17 \mathrm{~h}-40 \mathrm{~m}, 1$, hora a que executou uma oscillação, partindo de E. para W., com a amplitude de 2mm,40 (0”,62). Seguidamente registou-se uma serie de oscillaçôes, 7 das quaes de amplitude superior a $17 \mathrm{~mm}, 00$ (4",42), produzindo o deslocamento da posição d'equilibrio A amplitude das oscillaçôes diminuiu gradualmente até atingir $0 \mathrm{~mm}, 70(0$ ", 18$)$ às $18 \mathrm{~h}-10 \mathrm{~m}, 3$, em que voltou a augmentar, partindo o pêndulo de W. para E., e attingindo o valor de $1 \mathrm{~mm}, 40(0$ ”,36). Tornou a diminuir e parou, ás $18 \mathrm{~h}-55 \mathrm{~m}, 4$. Tremor domesticus. Epicentro em Benavente. Sentido em Coimbra com a força VI (Forel-Mercalli)” (Observações Meteorológicas, Magnéticas e Sísmicas, 1910).

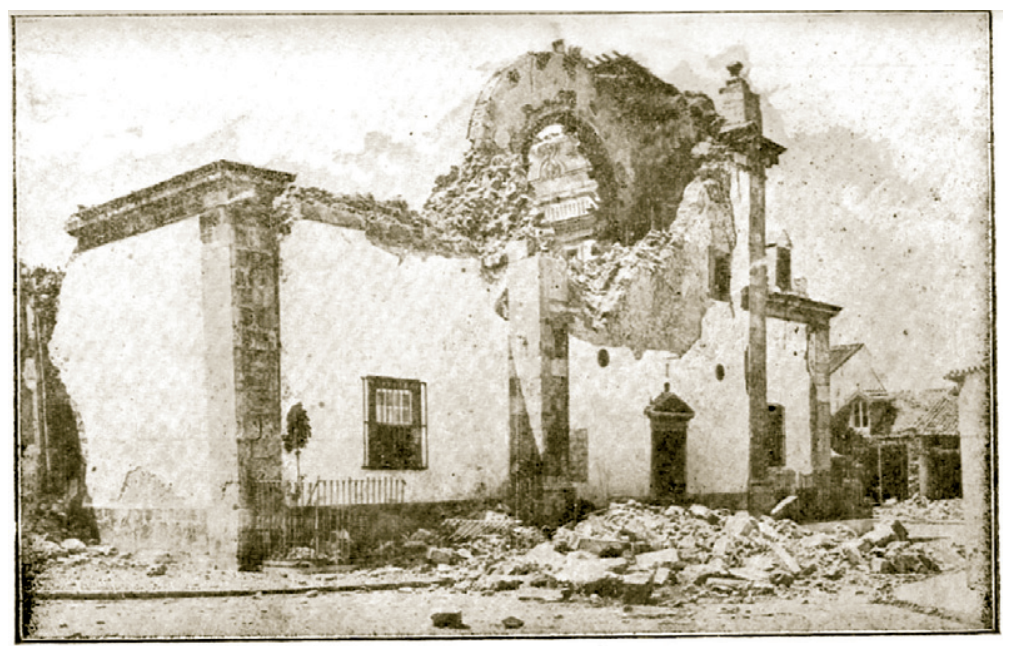

Figura 2: Efeitos do sismo de 23 de Abril de 1909 em Benavente (MIRANDA 1931a).

Várias cópias fotográficas do registo deste sismo foram fornecidas a entidades nacionais e estrangeiras, das quais destacamos a do sismólogo Manuel Sánchez Navarro-Neumann, do observatório espanhol da Cartuja, uma das primeiras a ser solicitada. O provimento, dado em 7 de Maio de 1909, foi acompanhada por um ofício de Santos Viegas, onde este descrevia alguns dos efeitos sentidos em Coimbra e noutras regiōes portuguesas, deu conta das réplicas registadas e solicitou uma cópia do sismograma obtido na estação da Cartuja (SANTOS 1995, pp. 151-152). Infelizmente, já não existe o sismograma original obtido em Coimbra: perdeu-se, provavelmente, devido a um empréstimo não registado.

Egas de Castro estudou este tremor de terra com vista a calcular a profundidade do hipocentro. O seu trabalho foi publicado num artigo n'O Instituto, em Novembro de 1909, com o título de Geodynamica tellurica (CASTRO 1909). O cálculo baseou-se na escala sísmica proposta por Cancani na 2. a Conferência Internacional de Sismologia, realizada em Estrasburgo em 1903, onde Portugal esteve representado (entre 18 países). A referida escala possuía doze termos (idênticos aos de Forel-Mercalli), designados por graus de "força de Cancani" (G), correspondendo, a cada um deles, valores limite de aceleração (A). Se não houvesse perda de energia, poderia supor-se

${ }^{5}$ A relação entre graus de força $(G)$ e valores de aceleração $(A)$ era obtida com base na equação $G=0,32+3 \log A$. 
que a aceleração sentida num determinado local era directamente proporcional à distância desse ponto ao foco do sismo. Dado existir absorção da energia do tremor de terra pela crusta terrestre, era possível obter um factor do decréscimo da aceleração baseado num coeficiente de absorção. Eram assim obtidas as chamadas "equaçôes de Cancani", que relacionavam os graus de força observados com a profundidade do foco e com o coeficiente de absorção da crusta terrestre. Este método pressupunha a elaboração de mapas com isossistas ${ }^{6}$, que permitiam obter as distâncias epicentrais (distância média de cada isossista ao epicentro). O mais importante era a recolha de observaçôes dos efeitos do sismo no maior número possível de pontos geográficos, atribuindo a cada um deles um grau de acordo com a escala de Cancani. Não tendo garantido o apoio da Comissão de Estudos Sísmicos, recentemente criada, Egas de Castro recorreu à imprensa para compilar uma relação de 125 localidades (na sua maioria nacionais, mas incluindo algumas espanholas), com as respectivas distâncias a Benavente, distribuídas por graus de força entre IX e IV (idem, pp. 591-593). Após calcular as respectivas distâncias médias, para cada grau de força (isossista), Egas de Castro obteve como resultados uma profundidade focal de $7,5 \mathrm{~km}$, um coeficiente de absorção de 0,0041 e a intensidade de $9,83^{\circ} \mathrm{em}$ Benavente, segundo a escala de Cancani (idem, pp. 598-599). Estes resultados foram confrontados por Egas de Castro com outros obtidos pelo mesmo método e correspondendo a outros nove sismos de intensidade semelhante, ocorridos desde 1885 . A única conclusão foi a elevada rigidez das camadas inferiores nacionais, tendo em conta o elevado valor do coeficiente de absorção.

Vários outros estudos sobre o sismo de 1909 foram publicados nos anos seguintes, principalmente por portugueses e espanhóis (CALDERÓN, 1909; COMAS SOLA, 1909; CABRAL, 1909; BENSAUDE 1910; NAVARRO-NEUMANN, 1910; DINIZ, 1910; CHOFFAT e BENSAUDE, 1912), destacando-se os que tiveram por base registos sismográficos (como o de Navarro-Neumann). Logo após o evento, o Ministro das Obras Públicas, Luís de Castro, nomeou duas comissões: uma para "o estudo dos methodos de construção em países sísmicos e para a reconstrução das regióes sinistradas" e outra para o estudo científico do sismo. A primeira iniciativa desta última comissão, da qual faziam parte Alfredo Bensaúde e Paul Choffat, foi a preparação de um questionário minucioso a ser distribuído pela população letrada. Com base nas respostas a este questionário, mas também na consulta da imprensa portuguesa e espanhola, e comparando os resultados com os estudos de Navarro-Neumann e Castro, Bensaúde e Choffat escreveram um extenso trabalho, publicado, em 1912, em francês, existindo uma tradução para português (CHOFFAT e BENSAUDE 1912). Léon Paul Choffat (1849-1819) era um geólogo suíço que veio a Portugal em 1878 para estudar a estratigrafia e a paleontologia dos terrenos jurássicos. Choffat acabou por em Portugal. Para além dos estudos geológicos, Choffat já tinha estudado os sismos de 1903 (CHOFFAT 1904). O açoriano Alfredo Bensaúde (1856-1941) foi um professor universitário e mineralogista muito reputado, célebre por ter sido

\footnotetext{
${ }^{6}$ Curvas que unem locais onde se verificou uma intensidade sísmica idêntica, ou seja com o mesmo grau de força $(G)$.

${ }^{7}$ Este não fez parte da primeira lista, mas entrou para substituir Francisco Ferreira Roquete.
} 
o principal fundador e também o primeiro director do Instituto Superior Técnico, em Lisboa, em 1911.

Egas de Castro também se tinha disponibilizado para participar na investigação de Choffat e Bensaúde. Contudo, em Fevereiro de 1910, foi enviado pela Direcção Geral de Instrução Superior um convite aos funcionários do Observatório de Coimbra, para a ocupação de um lugar de chefe de serviço encarregado das observaçôes magnéticas no Observatório de Ponta Delgada dos Açores. A primeira resposta de Egas de Castro, quando Santos Viegas lhe falou do convite, foi negativa, por estar à espera de ser desbloqueado orçamento para o lugar de encarregado da secção sísmica de Coimbra. No entanto, o impasse na aprovação do Orçamento de Estado desse ano, devido à crise política que antecedeu a revolução republicana de Outubro de 1910, impossibilitava o preenchimento do lugar em Coimbra, vendo-se Castro na contingência de contactar o director dos Serviços Meteorológicos dos Açores, Afonso Chaves, pedindo-lhe informações (CASTRO 1910). Francisco Afonso Chaves e Melo (1857-1926), Coronel do Exército, fundador e primeiro director do Serviço Meteorológico dos Açores, foi também um reputado geofísico, sendo o primeiro representante português na Comissão Permanente Internacional de Investigação de Sismos, criada em $1900 .^{8}$

Egas de Castro juntou à missiva que endereçou a Afonso Chaves, em 4 de Maio de 1910, o seu trabalho publicado n'O Instituto sobre o sismo de Benavente, referindo estar a redigir uma análise dos dados microssísmicos do mesmo tremor de terra a convite de Choffat e Bensaúde (idem). A partida para Ponta Delgada ocorreu em Setembro de 1910, permanecendo Castro nos Açores nos anos seguintes. Durante o tempo que passou nos serviços açorianos, Castro ter-se-á dedicado exclusivamente às observações magnéticas, não voltando a publicar mais nenhum trabalho de sismologia. Ocupou um lugar de professor interino no Liceu de Ponta Delgada. No estudo de Choffat e Bensaúde, vindo a lume em 1912, pode ler-se numa nota adicional:

\begin{abstract}
"Referiram-se os jornaes á colaboração n’este trabalho do Sr. Egas de Castro, do Observatório da Universidade de Coimbra. Sobre este assunto devemos declarar que effectivamente aquelle senhor manifestou a intenção de escrever um capitulo sobre as observações registadas nos differentes observatórios do globo. Apesar das instancias individuais de cada um de nós, não nos chegou até agora ás mãos nem o manuscrito nem resposta ás nossa cartas" (CHOFFAT E BENSAÚDE, 1912).
\end{abstract}

Castro regressaria ao Observatório de Coimbra, em Novembro de 1918, como observador-chefe. Menos de um ano depois e por motivos que desconhecemos, foi-lhe concedida licença ilimitada por despacho de 11 de Outubro de 1919 (ANUÁRIO da Universidade de Coimbra, 1919/20, p. 259)

Estudos mais recentes sobre o abalo de 1909 estabeleceram o seu valor de profundidade focal nos $10 \mathrm{~km}$ e um máximo de intensidade de IX, na escala modificada de Mercalli (STICH et al., 2005; TEVES-COSTA et al., 1999).

${ }^{8}$ Para além de ter integrado a primeira Comissão Internacional, Portugal foi também um dos 18 países signatários da convenção que, em Abril de 1904, instituiu a Associação Sismológica Internacional. 
O pânico desencadeado pelo sismo de 23 de Abril de 1909 teve o condão de alertar para a necessidade de organizar o serviço sismológico em Portugal (MIRANDA 1931c). Um movimento que envolveu a imprensa e o Parlamento venceu a inércia governamental ao suscitar a formação de um comité, composto pelos directores dos observatórios meteorológicos de Coimbra, Porto, Lisboa e Açores, com o objectivo de delinear uma proposta que materializasse o referido serviço (SIMÕES et al., 2009, p. 34). A insuficiente especialização técnica dos directores tornou algo improfícua a discussão, optando-se por estabelecer estações sismológicas nos observatórios nacionais já existentes, sem recorrer a critérios de localização baseados na sismicidade. Santos Viegas, apesar de achar úteis estes estudos, não viu vantagens em criar um grande número de estações (MIRANDA 1931c).

Em Janeiro de 1910, realizou-se em Lisboa, por proposta da Direcção Geral de Instrução Pública, uma conferência que juntou os directores dos observatórios nacionais e Choffat e Bensaúde, vogais da comissão nomeada em 27 de Abril. O objectivo era concretizar o "plano da organização do serviço de observações e estudos sismológicos em Portugal, comprehendendo a distribuição dos postos principaes e secundarios, e a escolha do typo de instrumentos para uns e outros" (SANTOS 1995 p. 158). Seriam delegadas no Observatório Infante D. Luís as funções de Estação Central de Sismologia, ficando as restantes estaçôes obrigadas a reportar qualquer evento registado. No entanto, esta iniciativa não viria a originar resultados uma vez que não foram estabelecidas disposiçōes que regulassem esta coordenação (PEIXOTO et al., p. 272).

Aproveitando a disposição de verbas consignadas pelo Orçamento de Estado para este efeito, os vários observatórios envidaram esforços para se equiparem no âmbito da sismologia. Assim, Afonso Chaves adquiriu dois sismógrafos de Milne, com registo fotográfico, quatro de Bosch e três sismoscópios de Cancani para os serviços açorianos (MIRANDA 1934, p. 13). Em Lisboa, no Observatório Infante D. Luís, foi, em 1909, montado um sismógrafo de Mainka que tinha sido oferecido a César Augusto de Campos Rodrigues (1836-1919), que era então director do Observatório Astronómico da Tapada da Ajuda, seguindo-se a instalação de dois sismógrafos de Wiechert. Campos Rodrigues coadjuvou também na instalação de um sismógrafo de Agamennone no Observatório da Serra do Pilar, no Porto, que seria terminada em 1912 (idem, pp. 10-11).

Também em Coimbra, no mesmo ano de 1910, Santos Viegas estabeleceu contactos com Wiechert ${ }^{9}$ para adquirir o sismógrafo horizontal, com uma massa inercial de uma tonelada. Devido à turbulência originada pela revolução republicana, verificou-se um atraso na entrega do instrumento, que só teve lugar a 19 de Julho de 1911 (SANTOS 1995, p. 162). Iniciou-se de imediato a construção de um pavilhão para o alojar. Todavia, dificuldades técnicas com a instalação do aparelho, que se prolongariam nos anos seguintes, retardaram a sua montagem, tendo Santos Viegas falecido, em 1914, em idade avançada, sem ver o sismógrafo em funcionamento. Seria o seu

${ }^{9}$ Este contacto com Wiechert foi estabelecido por intermédio de Bernard Tollens, químico alemão que tinha exercido funções docentes em Coimbra. 
sucessor na direcção do Observatório, Anselmo Ferraz de Carvalho (1878-1955), a concluir, no final de 1914, a instalação do referido sismógrafo.

Ferraz de Carvalho, professor da Faculdade de Ciências da Universidade e Coimbra e também sócio do Instituto, deu grande atenção aos trabalhos de sismologia. Com os dados produzidos pelos dois sismógrafos (Milne e Wiechert) iniciou em 1915 a publicação pelo observatório conimbricense de um boletim sísmico que era permutado com vários observatórios sismológicos estrangeiros, abrindo uma cooperação internacional nesta área (CARVALHO 1946, p. 7). Foi também mantido o intercâmbio dos resultados "do primeiro exame dos sismogramas mais interessantes" (análises sísmicas preliminares) com o Bureau Central Seismologique e com os serviços afins espanhóis e americanos (idem). Contudo, só em 1926 foi completado o equipamento necessário para uma estação sísmica de primeira categoria, ${ }^{10}$ projectada por Santos Viegas, com a aquisição de um novo sismógrafo de Wiechert, desta vez vertical (BATLLÓ et al. 2010). Com Ferraz de Carvalho também se verificou uma alteração da simbologia adoptada na publicação anual das observaçōes sismológicas, adoptando-se a nomenclatura de fases sísmicas de Mohorovicic ${ }^{11}$ (OBSERVAÇÕES Meteorológicas, Magnéticas e Sísmicas... 1918).

O ano de 1925, no decorrer do qual o Observatório da Universidade alterou a sua designação para Instituto Geofísico da Universidade de Coimbra, foi muito intenso no que respeita à actividade científica em Coimbra. Refira-se a inauguração da secção de astrofísica do Observatório Astronómico e a realização do Congresso Misto das Associações Portuguesa e Espanhola para o Progresso das Ciências. Ferraz de Carvalho, que era também vice-presidente do Instituto, publicou neste ano n'O Instituto um extenso trabalho sobre sismologia, Estudo actual dos tremores de terra (CARVALHO 1925), talvez o primeiro tratado científico sobre este tema publicado em Portugal.

Apesar da inacção, no que respeita à organização nacional dos serviços sismológicos, o Instituto Geofísico esteve sempre activo, tentando alargar a área de investigação para além dos registos sismográficos. Um exemplo desta determinação foi a distribuição de boletins sísmicos pelos inspectores do ensino primário, em 1926, que seriam enviados aos professores, para serem preenchidos na eventualidade de um tremor de terra (MIRANDA 1931a, p. 52). Os dados macrossísmicos dos terramotos posteriores a 1923 foram estudados no Instituto Geofísico, sendo estes resultados publicados por esta instituição em 1930 (MIRANDA 1930). O seu autor, Raúl de Miranda, efectuou uma comunicação intitulada Carácter sismico de Portugal Continental no decénio de 1923-1932 na Assembleia-Geral da União Internacional Geodésica e Geofísica, realizada em Lisboa em Setembro de 1933.

\section{O INTERCÂMBIO LUSO-ESPANHOL NO ÂMBITO DA SISMOLOGIA}

Santos Viegas manteve contactos estreitos com sismólogos estrangeiros, em particular com os seus colegas da Sociedade Sismológica Italiana, da qual também fazia parte o famoso sismólogo espanhol Manuel Maria Sánchez Navarro-Neumann

${ }^{10}$ Estação com a capacidade para registar todos os terramotos, próximos e afastados.

${ }^{11}$ Segundo esta nomenclatura, eram registados, com base nos sismogramas, os instantes de detecção: das vibrações longitudinal e transversal, das suas reflexôes na descontinuidade de Mohorovicic e das ondas longas (de superfície). 
(1867-1941), um padre jesuíta. ${ }^{12}$ Como vimos, logo na época do sismo de 1909 houve intercâmbio de sismogramas entre o Observatório de Coimbra e observatórios espanhóis, designadamente o Observatório da Cartuja, fundado por jesuítas de Granada em 1902, onde Navarro-Neumann era responsável pela área de sismologia desde 1905.

Em 1915, Navarro-Neumann publicou o seu primeiro artigo n'O Instituto, onde analisou algumas fórmulas aplicáveis a macrossismos, recorrendo a elas em exemplos reais como o sismo de Benavente, com base em alguns resultados do estudo de Egas de Castro (NAVARRO-NEUMANN 1915). ${ }^{13}$ Dois anos depois, a pedido de Francisco Miranda da Costa Lobo (1864-1945), presidente do Instituto, publicou um outro trabalho na revista $O$ Instituto, correspondente à conferência que apresentou no $6 .^{\circ}$ Congresso de Associação Espanhola para o Progresso das Ciências de 1917, realizado em Sevilha (NAVARRO-NEUMANN 1917). ${ }^{14}$ O estudo de Navarro-Neumann incidiu sobre os efeitos dos terramotos nos edifícios, de acordo com as observações recolhidas em diversos sismos, e no funcionamento dos sismógrafos, em especial os existentes no Observatório da Cartuja, e respectiva interpretação de sismogramas.

O intercâmbio científico entre Portugal e Espanha concretizou-se através da cooperação íntima entre as associações congéneres para o progresso das ciências, materializada em congressos conjuntos, o primeiro dos quais realizado na cidade do Porto, em 1921. Ressalva-se a comunicação de Vicente Inglada Ors (1879-1949), na qual este geofísico e astrónomo espanhol, director de sismologia do Observatório de Toledo (de 1910 a 1923), usou um novo método para calcular a profundidade do foco sísmico aplicado ao sismo de Benavente de 1909, tendo por base o estudo de Choffat e Bensaúde (INGLADA 1921). Inglada Ors obteve como valor final a profundidade de $3,25 \mathrm{~km}$ (CARVALHO 1925 , p. 105). No referido congresso de Coimbra, em 1925, também esteve presente Inglada Ors que, no discurso inaugural da 2. Secção de Astronomia e Física do Globo, falou do Rápido progresso de las ciências telúricas. Também neste congresso, Ferraz de Carvalho apresentou uma comunicação onde apelava à Colaboração intima dos serviços sismológicos de Espanha e Portugal, tendo proposto a "transmissão rápida e gratuita de telegramas com os dados mais importantes dos sismos registados. "15

Inglada Ors, no seu estudo sobre o sismo de Bajo Segura, de 10 de Setembro de 1919, utilizou, para o cálculo das coordenadas do foco baseado na hora inicial, os sismogramas registados em várias estações próximas na península ibérica (Alicante, Almería, Cartuja (Granada), Ebro (Tortosa), Fabra (Barcelona), San Fernando, Toledo e Málaga e a de Coimbra. Ambos os países integraram a primeira lista mundial de estações sismológicas, compilada pela Secção de Sismologia da União Geofísica Americana e publicada em

${ }^{12}$ Biografia e bibliografia de Navarro-Meumann em http://www.ugr.es/-iag/ins/cd/i/sanchznv.pdf (consultado em 27 de julho de 2011).

${ }^{13}$ Navarro-Neumann também estabeleceu contactos com os jesuítas portugueses. Publicou na Broteria (Revista contemporanea de cultura) os seguintes artigos: Os terremotos observados sem o auxilio de instrumentos. (vol. VI, 1907, p. 217-250); O recente terremoto de Messina, (vol. VII, 1909, pp. 100-110, fig. 4 (pp. 1-10)); Os ultimos descobrimentos em Sismologia, (vol. XII, 1914, pp. 36-53 (pp. 1-17)); O estado atual da Sismologia, (XI, 1930, pp. 29-34); Os Jesuitas e a Sismologia. (XXIV, 1937, pp. 145-151); Jesuitas astronomos, (XXIV, 1937, pp. 433-457).

${ }^{14}$ Este congresso teve algum destaque n'O Instituto devido à presença de vários portugueses, entre os quais Costa Lobo e Gomes Ferreira, em representação do Instituto de Coimbra e da recentemente criada Associação Portuguesa para o Progresso das Ciências.

${ }^{15}$ Trabalhos scientíficos anunciados e na quási totalidade apresentados ao Congresso (1925), O Instituto, vol. 71, p. 626. 
1921. A rede sísmica espanhola era mais extensa, com nove estações, enquanto Portugal surgia apenas com três postos: em Coimbra, Lisboa e Ponta Delgada (WOOD 1921).

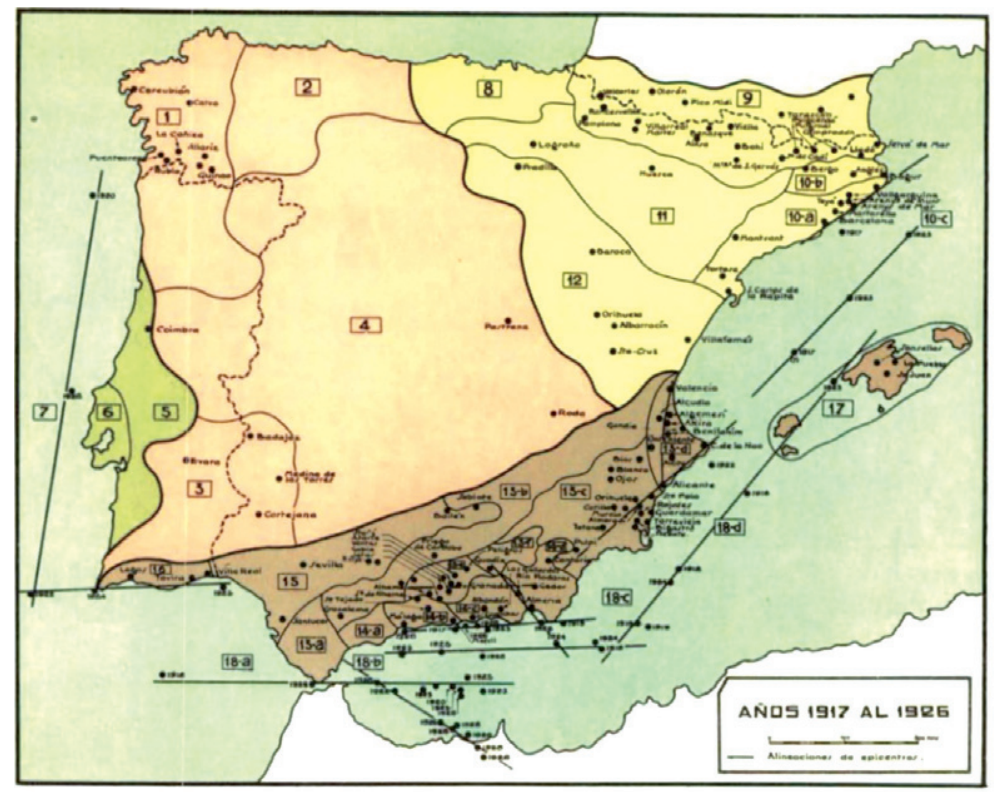

Figura 3: Zonas sísmicas da Península Ibérica (REY PASTOR 1927).

As principais zonas sísmicas nacionais (e ibéricas) foram sendo delineadas, destacando-se o trabalho do já referido geólogo e capitão do exército português Francisco Luís Pereira de Sousa (1870-1931), autor do trabalho sobre o sismo de 1755 e que caracterizou sismicamente a região de Lisboa (MIRANDA 1934). No entanto, o desejado serviço sismológico em Portugal mantinha-se inactivo. Em Coimbra emergiu então a figura de Raúl Fernandes Ramalho de Miranda (1902-1978), assistente da Faculdade de Ciências da Universidade de Coimbra, que publicou em 1931 o livro Tremores de Terra (MIRANDA 1931a), dedicado a Navarro-Neumann ${ }^{16}$. Neste mesmo ano, Miranda fundou em Coimbra a primeira revista portuguesa de Geofísica - A Terra, dirigida e mantida à sua própria custa. Esta publicação, que se manteve ao longo de sete anos, agregou os mais importantes artigos nesta área de investigadores portugueses e estrangeiros. Um dos colaboradores desta revista era Alfonso Rey Pastor (1890-1959), director da estação sismológica de Toledo e do serviço sismológico espanhol, que publicou aí um artigo descrevendo esse organismo (REY PASTOR 1931). Em 1927, Rey Pastor publicou também um livro, onde explanou de forma pormenorizada as características sísmicas da Península Ibérica - figura 3 (REY PASTOR 1927). ${ }^{17}$ Miranda

16 "Ao eminente sismologo espannol e sabio ilustre, D. Manuel María Sánchez Navarro-Neumann, con o maior apreço pola sua obra notavel, muito afectuosemente, e affmo. Dr. Raul de Miranda, Catedratico de Física del Globo en la Universidad de Coimbra, autor de: Tremores de terra”.

${ }^{17}$ No IV Congresso [da] Associação Portuguesa para o Progresso das Ciências, celebrado na cidade do Porto 
daria continuidade ao trabalho de Pereira de Sousa e de Choffat, quer na catalogação dos sismos portugueses quer no estudo da sismicidade das regiōes portuguesas.

\section{CONSIDERAÇÕES FINAIS}

Após o estabelecimento do Estado Novo, em 1933, a sismologia tornou-se um assunto ausente das preocupações políticas. Apenas a estação de Coimbra mantinha nesta altura contactos internacionais (MIRANDA 1931b). Apesar da tentativa de Raúl de Miranda de relançar este tema, sugerindo a criação de uma rede nacional de estações sísmicas, oito no território continental (para além de Coimbra, Lisboa e Porto, propunha-se a criação de estações em Viana do Castelo, Santarém, Setúbal, Évora e Faro, de forma a permitir a detecção de tremores débeis e com área de propagação reduzida, originados nas diversas zonas sísmicas nacionais), com o Instituto Geofísico de Coimbra a ser a estação central deste serviço (MIRANDA 1931b), a actividade portuguesa em sismologia entraria em declínio ao longo da década de $1930 .{ }^{18}$ Situação similar sucedeu em Espanha, onde se desencadeou a guerra civil de 1936 a $1939 .{ }^{19}$

Apesar da fundação em Coimbra, em 1933, da Sociedade de Meteorologia e Geofísica de Portugal, que tinha Anselmo de Carvalho como presidente honorário, nenhuma das comunicações efectuadas no âmbito desta associação (durante os curtos anos da sua actividade) incidiu especificamente na sismologia. Em 1946, com a criação do Serviço Meteorológico Nacional, o Instituto Geofísico de Coimbra foi integrado neste organismo, perdendo a sua autonomia, o que justificou o pedido de exoneração do director Anselmo de Carvalho. Este último havia sucedido, em 1945, como presidente do Instituto a Costa Lobo. O Serviço Meteorológico Nacional pouco ou nada trouxe de novo no que respeita à organização da sismologia em território nacional, ${ }^{20}$ sendo apenas retomados os estudos macrossísmicos, abandonados de 1930 até 1940.

Um último artigo sobre sismologia foi publicado n'O Instituto, em 1953, aquando da comemoração do centenário da sociedade científica e literária coimbrã sob cuja égide era editada a revista. O seu autor foi António Romañá Pujó (1900-81), director do observatório espanhol do Ebro, jesuíta como Navarro-Neumann, que ensaiou uma explicação para a frequência dos terramotos (ROMANA 1951).

O estudo de Egas de Castro, de 1909, e a memória de Anselmo de Carvalho, de 1925, publicados n'O Instituto, são marcos na história da sismologia em Portugal. A relevância do estudo de Egas de Castro é reconhecida por Navarro-Neumann no seu primeiro artigo, na mesma revista, de 1915. Embora os artigos de Navarro-Neumann, Inglada Ors e Romaña Pujó, que aqui referimos, não tenham a mesma relevância histórica para a sismologia espanhola, eles expressam a vontade dos seus autores de

de 18 a 24 de junho de 1942 juntamente com o XVII Congresso da Associação Espanhola para o Progresso das Ciências / Associação Portuguesa para o Progresso das Ciências, Rey Pastor apresentou o trabalho intitulado Contribución de la sismologia a los estudios geográficos : la region sudeste de la Peninsula Ibérica.

${ }^{18}$ Inclusivamente, verifica-se que o número de artigos sobre sismologia publicados na revista $A$ Terra reduz-se, significativamente, até 1935, deixando de existir nos últimos volumes deste periódico.

${ }^{19} \mathrm{O}$ declínio da sismologia foi geral na Europa, da segunda metade dos anos vinte até a segunda grande guerra.

${ }^{20}$ No decreto-lei 35836, de 29 de agosto de 1946, que criou este serviço, não surge uma única referência à sismologia. 
darem a conhecer as suas investigações no país vizinho e demonstram a existência de intercâmbio científico entre os dois países ibéricos nesta área da geofísica.

\section{Agradecimentos}

Agradecemos à Fundação Portuguesa para a Ciência e Tecnologia pelo apoio financeiro que tornou possível a catalogação da biblioteca e arquivo do Instituto de Coimbra, na Biblioteca Geral da Universidade de Coimbra; pela bolsa de estudos concedida ao primeiro autor; e também pelo financiamento do projecto HC/0119/2009: "História da Ciência da Universidade de Coimbra (1547-1933)".

\section{REFERÊNCIAS}

ALMEIDA, A. de The 1755 Lisbon earthquake and the Genesis of the risk Management Concept. In MENDES-VICTOR, Luis Alberto; Oliveira, C. S.; Azevedo, J.; Ribeiro, A. The 1755 Lisbon Earthquake: Revisited. Berlin: Springer, 2009. p. 147-165.

BATLlÓ, J.; CUSTÓDIO, S.; NARCISO, J.; RIBEIRO, P.; LOPES, F.; MARTINS, D.; E GOMES, C. A História da Sismologia no Instituto Geofísico da Universidade de Coimbra. Revista Eletrónica de Ciências da Terra-Geosciences On-line Journal. [Em linha]. 15:5 (2010). 1-4. [Consult. 2010] Disponível em WWW:<URL:http://hdl.handle.net/10316/14254>

BENSAUDE, A. (19??). Le tremblement de terre de la vallée du Tage de 23 Avril 1909 (note preliminaire). Bulletin de la Soc. Port. Des. Sc. Nat. t. IV, p. 89-129. 2 cartes, Lisbonne 1909. (Publicado em maio 1910). Copiado de Choffat \& Bensaude (1912), p. 12.

CABRAL, F.P. - Algumas notas sobre o tremor de terra de 23 de abril. Broteria.VIII: 182 (1909).

CALDERÓN, S. - Nota sobre el terremoto sentido en la Península Ibérica el 23 de abril de 1909. Bolet Real Socidade Espanola de Historia Natural. Vol. IX (1909), p. 219-233.

CARVALHO, Anselmo Ferraz de - O estudo atual dos tremores de terra. O Instituto. 72 (1925) 87-134.

CARVALHO, Anselmo Ferraz de - Trinta e Dois anos na Direção do Instituto Geofísico de Coimbra. Breve relatório apresentado à Faculdade de Ciências. Coimbra: Atlântida, 1946.

CARVALHO, Rómulo de - As interpretaçōes dadas, na época, às causas do terramoto de 1 de novembro de 1755 . Memórias da Academia das Ciências de Lisboa. Lisboa: [s.n.], 1987. p. 179-205. (Classe de Ciências; tomo 28)

CASTRO, Egas de - Geodynamica tellurica. Cálculo provisório do hipocentro do sismo de 23 de abril de 1909. O Instituto. Vol. 56 (1909) p. 586-599.

Idem 1910-1914. Correspondência de Egas de Castro com Afonso Chaves (pertencente ao Fundo José Agostinho da Biblioteca Pública e Arquivo Regional de Angra do Heroísmo).

CHOFFAT, Paul Léon - Les tremblements de terre de 1903 en Portugal. Communicações da Commissão do Serviço Geologico de Portugal. Tomo V (1904), p. 279-306.

CHOFFAT, Paul Léon; BENSAUDE, Alfredo - Estudos sobre o sismo do Ribatejo de 23 de abril de 1909. Lisboa: Comissão dos Serviços Geológicos Portugueses, 1912.

COMAS SOLÀ, José - Nota sobre el terremoto olotino del 6 de abril de 1909 y el terremoto peninsular del 23 de abril de 1909: cálculo de la profundidad hipocentral. Memoria Real Academia Ciencias y Artes de Barcelona. Vol. 8 (1909) p. 75-84.

COSTA, Augusto Ramos da - Para a história da sismologia portuguesa, em 1909. A Terra - revista portuguesa de geofisica. Vol. 5 (1931), p. 10.

CUSTÓDIO, Susana.; RIBEIRO, Paulo ; MARTINS, Décio R.; NARCISO, João; BATLLÓ, Josep.; LOPES, Fernando C.; GOMES, Celeste R. - The Historical Collections of the Geophysical Institute Of The University Of Coimbra, and Their Use For Modern Science. In BRANDÃO, J. M., ed. [et al.] Collections and Museums of Geology: mission and management. Coimbra: Museu Mineralógico e Geológico da Universidade de Coimbra [etc.] (2010), p. 167-178.

DINIZ, José de Oliveira Ferreira - Contribuição para o Estudo dos Tremores de Terra em Portugal. O abalo sísmico de 23 de abril de 1909. Rev Obras Públ Minas. Lisboa: [s.n.] (1910), p. 483-484.

FERRARI, Graziano - Seismograph. Instruments of Science. An Historical Encyclopedia. London: The Science Museum [etc.], 1998. p. 528-530.

FERRARI, Graziano; GUIDOBONI, Emanuela - Seismic scenarios and assessment of intensity: some criteria 
for the use of the MCS scale. Annals of Geophysics. Vol. 43:4 (2000), p. 708-720. www.annalsofgeophysics.eu/ index.php/annals/article/view/3664/3723

FONSECA, J. F. B. D.; E VILANOVA, S. P. - The 23 April 231909 Benavente (Portugal) M 6.3 Earthquake. Seismological Research Letters. 81:3 (2010), p. 534-536.

HOWELL, Benjamin F. Jr. - An Introduction to Seismological Research. History and Development. Cambridge: Cambridge University Press, 1990.

INGLADA Ors V. - Cálculo de la profundidad hipocentral del sismo del Ribatejo (Portugal) de 23 de abril de 1909. Proc Asoc Esp Progr Cienc, Oporto: [s.n.]. IV:2 (1921), p. 89-107.

LEONARDO, A. J. F.; MARTINS, Décio. R.; FIOLHAIS, Carlos - O Instituto de Coimbra: breve história de uma academia científica, literária e artística. In MAIA DO AMARAL, A. E., coord. Tesouros da Biblioteca Geral da Universidade de Coimbra. Coimbra: Imprensa da Universidade, 2009. p. 115-125.

LEONARDO, A. J. F;; MARTINS, Décio. R.; FIOLHAIS, Carlos. The Meteorological Observations in Coimbra and the Portuguese participation in Weather Forecast in Europe. Earth Sciences History. Vol. 30:1 (2011), p. 135-162.

MENDONÇA, José Moreira - História Universal dos Terremotos que tem havido no mundo, de que ha noticia, desde a sua creaçaõ até o seculo presente...Lisboa: na offic. de Antonio Vicente da Silva, 1758.

MIRANDA, Raúl de - Tremores de terra em Portugal (1923-1930). Coimbra: Instituto Geofísico da Universidade de Coimbra, 1930.

MIRANDA, Raúl de -Tremores de terra: estudo macrosísmico. Coimbra: Silva Raposo \& CaL.da, 1931.

MIRANDA, Raúl de - Organização sismológica em Portugal. A Terra - revista portuguesa de geofísica. Vol. 2 (1931), p. 47.

MIRANDA, Raúl de - O Sismo de Benavente e a tentativa de organização do serviço sismológico em Portugal. A Terra - revista portuguesa de geofisica Vol. 4 (1931), p. 28.

MIRANDA, Raúl de - O problema da Sismologia em Portugal no duplo aspeto científico e humano A Terra revista portuguesa de geofisica. Vol. 16 (1934), p. 5.

MUSSON, R.; GRÜNTHAL, G.; AND STUCCHI M., - The Comparison of Intensity Scales. Journal of Seismology. Vol. 14 (2010), p. 413-428.

NAVARRO-NEUMANN, Manuel Maria S. (1910). Le tremblement de terre Iberique du 23 Avril 1909. Ciel e Terre, XV, p. 41-66.

NAVARRO-NEUMANN, Manuel Maria S. - Essai de quelques formules applicables aux macrosismes. O Instituto. Vol. 62 (1915), 529-535.

NAVARRO-NEUMANN, Manuel Maria S. - El terramoto y los edificios. El sismographo. O Instituto. Vol. 64 (1917), p. 435-452; 515-532.

OBSERVAÇÕES meteorológicas, magnéticas e sísmicas. I.G..U.C. Vol. 49 (1909)-vol 57 (1918). Coimbra: Imprensa da Universidade, 1909-1918.

PEIXOTO, J. Pinto ; FERREIRA, José F. V. G. - As Ciências Geofísicas em Portugal. História e desenvolvimento da ciência em Portugal. Lisboa, 1986.

REY PASTOR, Alfonso - Traits Sismiques de la Péninsule Ibérique. Madrid: Ateliers de L’Institut Geographique et Cadastral, 1927.

REY PASTOR, Alfonso - El servicio sismológico español. A Terra - revista portuguesa de geofisica. Vol. 1, p. 20; vol. 2, p. 36, vol. 3, p. 18 .

ROMANÁ PUJÓ, António - Sobre a posible explication térmica del período anual en la frecuencia de los terremotos. O Instituto. Vol. 115 (1951), p. 102-117.

SANTOS, Vitorino Gomes de Seiça e - O Instituto Geofísico da Universidade de Coimbra (Bosquejo histórico). 1995. 390 p. Acessível na biblioteca do Institulo Geofísico da Universidade de Coimbra, Portugal.

SIMÕES, Ana; CARNEIRO, Ana; DIOGO, M. Paula. 2009. What can news about earthquakes, volcanoes and eclipses tell us? Science in the Portuguese press at the beginning of the 20th century. Communicating Science in $20^{\text {th }}$ Century Europe. A survey on research and comparative perspetives (Anne Schirrmacher Ed.). Max Planck Institute for the History of Science, 27-43.

STICH, Daniel; BATLLÓ, Josep; MACIÀ, Ramon; TEVES-COSTA, Paula; MORALES, Jose - Moment tensor inversion with single-component historical seismograms: The 1909 Benavente (Portugal) and Lambesc (France) earthquakes. Geophysical Journal International. Vol. 162 (2005), p. 850-858.

TEVES-COSTA, Paula; BATLLÓ, Josep - The 23 April 1909 Benavente earthquake (Portugal): macroseismic field revision. Journal of Seismology. [Em linha]. 15:1 (2010), 59-70- [Disponível em WWW:<URL: http:// link.springer.com/content/pdf/10.1007\%2Fs10950-010-9207-6>.

VALONE, David A. - Seismology: Disciplinary History. Sciences of the Earth - An Encyclopedia of Events, People and Phenomena. [S.1.]: Garland Publishing, 1998. p. 745-749.

WOOD, H.O. - A list of Seismologic Stations of the World. Bulletin of the National Research Council, National Academy of Sciences. Washington D.C. 2:15 (1921). Pt 7. 